\title{
P02-2-17 Poster session
}

\section{Menthol gel for the management of neuropathic pain after hand surgery - a case report}

\author{
Hannu Kokki ${ }^{1}$, Merja Kokki ${ }^{2}$ \\ ${ }^{I}$ Department of Anaesthesiology and Intensive Care, School of Medicine, University of Eastern Finland, Kuopio, \\ Finland, ${ }^{2}$ Department of Anaesthesia and Operative Services, Kuopio University Hospital, Finland
}

\section{Background}

The prevalence of neuropathic pain varies between $1.3 \%$ and $18 \%$. It affects the quality of life significantly and has important social and economic consequences (1). Complex regional pain syndrome (CRPS) is one of the most severe neuropathic pain conditions. Up to $26 \%$ of patients with surgical treatment of traumatic hand injuries may develop CRPS (2).

Menthol has been used for analgesia since ancient times. Recent interest in menthol for pain management has risen since 2002 when the menthol sensing channel transient receptor potential melastatin 8 was identified (3, 4). Since, menthol has been shown to be effective in management of several acute, inflammatory and neuropathic pain.

Here we present a case report where menthol was used in the treatment of refractory CRPS after traumatic hand injury and surgery.

Case

A 39-year-old non-smoking healthy male had traumatic complete tear of the distal biceps tendon on June 2017. Two days later, surgery was performed to reattach the tendon to the bone. After surgery, he developed severe lancinating neuropathic pain at the elbow. Pain was worse at night-time, NRS 7-8/10 and he could sleep 3-4 h a night. Paracetamolcodeine and tizanidine were ineffective, gabapentin had some effect, but he was so somnolent that he could not return to work. Four weeks after the primary injury he was prescribed menthol-gel (IcePower ${ }^{\circledR}$, Fysioline Ltd., Tampere, Finland) for day-time use and menthol patches at night on the elbow. Starting the first night, he could sleep 6-7 h a night, his pain rating decreased to 3-5/10, he returned to work and after 4 weeks of treatment he could stop the menthol use. Six months after injury, the muscle function has been restored. He sometimes has some muscle aches a few nights a week, which are relieved with menthol gel. During the day, he has no pain or other symptoms.

Conclusions

Menthol could be highly potent in persistent postoperative/posttraumatic pain management.

References

1. Inoue S, et al. Eur J Pain 2017;21:727-37.

2. Savas S, et al. J Hand Ther2017, doi: 10.1016/j.jht.2017.03.007

3. McKemy DD, et al. Nature 2002;416:52-8.

4. Peier AM, et al. Cell 2002;108:705-15. 